\title{
Identification of the major outer membrane proteins of Aeromonas salmonicida
}

\author{
Roger O. Ebanks*, Michel Goguen, Stewart McKinnon, Devanand M. Pinto, Neil W. Ross
}

Institute for Marine Biosciences, National Research Council Canada, 1411 Oxford Street, Halifax NS B3H 3Z1, Canada

\begin{abstract}
Aeromonas salmonicida subsp. salmonicida is a Gram-negative bacterium that is the etiological agent of furunculosis, a serious infectious disease of salmonids. Aeromonas spp. are ubiquitous waterborne bacteria responsible for a wide spectrum of diseases among aquatic organisms and humans. Bacterial outer membrane proteins (OMPs) play a significant role in virulence as they comprise the outermost surface in contact with host cells and immune defense factors. To identify the major OMPs of A. salmonicida a proteomic analysis was undertaken using a carbonate OMP-enrichment protocol. The enriched OMP-extracts were separated by 2-dimensional electrophoresis (2-DE) and the spots identified using liquid chromatography/mass spectrometry/mass spectrometry (LC/MS/MS) via an electrospray ionization source. In total, 76 unique proteins were identified from the 125 spots observed on the 2-D gel. The surface layer (S-layer) VapA protein dominated the $A$. salmonicida OMP 2-D profile, accounting for $60 \%$ of the protein on the 2-D gels. Among the other outer membrane proteins identified were at least 10 porins and various receptors involved in nutrient acquisition. Also identified in the carbonate insoluble fraction were phosphoglycerate kinase, enolase and others that lacked classical export sorting signals. The putative association of these proteins with the cell surface might provide new insights concerning the biological and pathogenic roles of these molecules in $A$. salmonicida infection. This work represents the first systematic attempt to characterize the cell surface of $A$. salmonicida.
\end{abstract}

KEY WORDS: Proteomics · Aeromonas salmonicida $\cdot$ Outer membrane proteins

\section{INTRODUCTION}

Aeromonas salmonicida subsp. salmonicida is a Gram-negative, non-motile, rod-shaped, facultative intracellular, gamma proteobacterium. This species causes a generalized septicaemia in fish; however, only A. salmonicida subsp. salmonicida causes furunculosis, a disease of farmed and wild salmonids. This disease incurs significant costs upon salmon farmers through direct, as well as indirect costs associated with treatment and vaccination. A related Aeromonas species, A. hydrophila, is a pathogen of humans, invertebrates and fish. In humans Aeromonas spp. have been implicated in outbreaks of diarrhoeal disease and wound infections and can produce serious systemic infections in immunocompromised individuals (Janda \& Duffey 1988, Janda \& Kokka 1991).

The cell wall of Aeromonas salmonicida is composed of 4 morphologically defined structures: the cyto- plasmic membrane, the peptidoglycan layer, the outer membrane and an exterior layer, termed the surface layer (S-layer) (Glauert \& Thornley 1969). This S-layer is composed of identical protein subunits of the VapA protein having the ability to self-assemble into a 2dimensional crystalline array which completely covers the cell surface during all stages of growth and division (Beveridge et al. 1997, Sleytr \& Beveridge 1999, Sara \& Sleytr 2000). The S-layer is tightly anchored to the cell by binding to the $\mathrm{O}$ side chain of lipopolysaccharide (LPS). The S-layer plays an essential role in bacterial virulence. The S-layer protein has been shown to play a role in providing protection against the bactericidal effects of immune and non-immune serum (Munn et al. 1982), in protecting the bacteria from damaging environmental agents such as proteases (Chu et al. 1991, Kostrzynska et al. 1992), and promoting adhesion to a variety of surfaces and cells (Phipps \& Kay 1988, Doig et al. 1992, Garduno et al. 1992, Trust et al. 1993). 
Ishiguro and co-workers showed that loss of the Slayer protein results in a subsequent loss of virulence (Ishiguro et al. 1981).

Because of their location at the host-bacterial interface, the outer membrane proteins (OMPs) of bacterial pathogens have been of particular interest with respect to host immune responses and as targets for drug therapy. To date, other than the S-layer, a limited number of Aeromonas salmonicida OMPs have been identified. Costello and co-workers reported that A. salmonicida expresses 2 OmpA porin family gene products (OmpAI and OmpAII) coded for by 2 distinct genes (Costello et al. 1996). Other A. salmonicida surface proteins identified include a maltose-inducible LamB homolog (Dodsworth et al. 1993), the ExeD protein of the general secretion pathway used to translocate extracellular proteins from the periplasmic space across the outer membrane (Karlyshev \& MacIntyre 1995), a 43 and a $28 \mathrm{kDa}$ OMP involved in pore-forming activity (Darveau et al. 1983, Lutwyche et al. 1995). In response to growth under iron-restricted conditions, A. salmonicida up-regulates a number of outer-membrane proteins termed iron-regulated OMPs (IROMPs) (Chart \& Trust 1983, Hirst et al. 1991, Neelam et al. 1993, Fernandez et al. 1998). Work by Hirst \& Ellis (1994) previously identified the IROMPs as being immunoprotective against $A$. salmonicida. They identified 4 IROMPs of molecular mass $82,77,72$ and 70 $\mathrm{kDa}$, up-regulated in response to 2,2'-dipyridyl. The work of Chart \& Trust (1983) identified 3 iron-regulated OMPs with apparent molecular weights of 83, 78 and $76 \mathrm{kDa}$. We have shown that in response to low iron growth, A. salmonicida up-regulates 3 OMPs, identified by mass spectrometry as: a $73 \mathrm{kDa}$ siderophore receptor, a $76 \mathrm{kDa}$ outer membrane heme receptor, and an $85 \mathrm{kDa}$ ferric siderophore receptor (Ebanks et al. 2004). When cultured in vivo within dialysis tubing placed within the peritoneal cavity of salmon, A. salmonicida up-regulated identical 73, 76 and $85 \mathrm{kDa}$ proteins (Ebanks et al. 2004).

Various methods have been used to enrich for OMPs (Logan \& Trust 1983, Bjornsdottir et al. 1992, Molloy et al. 2000). The carbonate extraction procedure was chosen because it is rapid, reproducible, and compatible with subsequent micro-preparative separations. The carbonate treatment converts vesicles into membrane sheets and, in the process, removes soluble and adsorbed proteins. The insoluble integral membrane proteins are then recovered by centrifugation. This method has been used to characterize the outer membrane proteome of a number of bacterial pathogens (Molloy et al. 2000, Nouwens et al. 2000, Phadke et al. 2001, Blonder et al. 2002).

This work represents the first systematic proteomic analysis of the surface proteins of Aeromonas salmoni- cida. In this paper, we describe the characterization of the major OMPs of $A$. salmonicida under standard growth conditions, as well as in response to low iron stress. The proteins were separated and identified by 2-D gel electrophoresis and LC/MS/MS analysis. This outer membrane proteomic analysis will serve as a reference map for subsequent studies on the response of A. salmonicida to various growth and culture conditions associated with infection, virulence, and pathogenicity.

\section{MATERIALS AND METHODS}

Aeromonas salmonicida strains and growth conditions. A. salmonicida subsp. salmonicida strain A449 was isolated from a disease outbreak in brown trout Salmo trutta in Normandy, France. Strain IMB 97-15 is a laboratory derived avirulent and S-layer deficient mutant. All strains were cultured to mid-exponential growth from frozen glycerol stocks in tryptic soy broth (TSB, Difco) with agitation at $17^{\circ} \mathrm{C}$. Iron-limiting conditions were created by the addition of $2,2^{\prime}$-dipyridyl to TSB (final concentration $120 \mu \mathrm{M}$ ). Bacterial number was estimated by absorbance at $600 \mathrm{~nm}$. A more accurate estimate of bacterial number was achieved by direct colony counts on tryptic soy agar (TSA, Difco) after incubation at room temperature for $24 \mathrm{~h}$.

OMP extraction. OMPs were obtained using a modified carbonate extraction method reported by Fujiki et al. (1982). The phosphate-buffered saline (PBS)-washed bacterial pellet was resuspended in cold $50 \mathrm{mM}$ Tris$\mathrm{HCl}, 2$ mM EDTA buffer, pH 8.0, containing a protease inhibitor cocktail (cocktail set 2, Calbiochem). The bacterial suspension was lysed using a French press operating at $16000 \mathrm{psi}$. The resulting lysate was centrifuged at $5000 \times g$ to remove unbroken cells. The supernatant was then pelleted at $115000 \times g$ and the resulting membrane pellet extracted for $1 \mathrm{~h}$ with ice-cold $100 \mathrm{mM}$ sodium carbonate, pH 11.0. Carbonate insoluble membranes were collected by centrifugation at $115000 \times g$ for $1 \mathrm{~h}$. The membrane-containing pellet was resuspended in $50 \mathrm{mM}$ Tris- $\mathrm{HCl}, \mathrm{pH} 8.0$ and centrifuged again at $115000 \times g$ for $30 \mathrm{~min}$ to remove contaminating soluble proteins. The final pellet was re-suspended in rehydration buffer (7 M Urea, 2 M Thiourea, $2 \%$ CHAPS). Protein concentration was assessed by a Bradford assay (Bradford 1976) using bovine $\gamma$-globulin as a reference.

2-D gel electrophoresis. Protein samples (300 to $400 \mu \mathrm{g}$ total carbonate extracted protein) were diluted 1:10 with rehydration buffer containing $2 \mathrm{mM}$ dithiothreitol (DTT) and 0.5\% carrier ampholytes, and applied to $18 \mathrm{~cm}$ immobiline drystrips $\mathrm{pH} 4-7$ or $\mathrm{pH} \mathrm{3-10}$ (Amersham-Pharmacia). Isoelectric focusing was carried out using the Multiphor II system (Amersham- 
Pharmacia). Focusing was initiated at $30 \mathrm{~V}$ for $10 \mathrm{~h}$ and then increased to $8000 \mathrm{~V}$ over a $6 \mathrm{~h}$ period, and held at $8000 \mathrm{~V}$ for $3 \mathrm{~h}$. The sample strips were then equilibrated in $50 \mathrm{mM}$ Tris- $\mathrm{HCl} \mathrm{pH}$ 8.8, $6 \mathrm{M}$ Urea, $30 \%$ (v/v) glycerol, $2 \%$ sodium dodecyl sulphate (SDS), $65 \mathrm{mM}$ dithiothreitol, then equilibrated for a second time with $50 \mathrm{mM}$ TrisHCl pH 8.8, 6 M Urea, $30 \%$ (v/v) glycerol, $2 \%$ SDS, $135 \mathrm{mM}$ iodacetamide. The second dimension was run on an $18 \times 20 \mathrm{~cm} \times 1 \mathrm{~mm}$ thick, $14 \% \mathrm{~T}(\mathrm{~T}=$ total concentration in \%) sodium dodecyl sulphate polyacrylamide gel electrophoresis (SDS-PAGE gel), run for $2100 \mathrm{Vh}$. The proteins were visualized using silver staining (Shevchenko et al. 1996).

In-gel trypsin digestion. The excised gel spots were placed into 96-well plates, washed 3 times, each for $10 \mathrm{~min}$, with $100 \mu \mathrm{l}$ of $50 \%$ acetonitrile (ACN) in 25 $\mathrm{mM} \mathrm{NH}_{4} \mathrm{HCO}_{3}$, and then dehydrated in $200 \mu \mathrm{l}$ of $100 \%$ ACN for $10 \mathrm{~min}$. Proteins were reduced with $200 \mu \mathrm{l}$ of $10 \mathrm{mM}$ DTT in $25 \mathrm{mM} \mathrm{NH}_{4} \mathrm{HCO}_{3}$ at $56^{\circ} \mathrm{C}$ for $1 \mathrm{~h}$, followed by alkylation in $200 \mu \mathrm{l}$ of $25 \mathrm{mM} \mathrm{NH}_{4} \mathrm{HCO}_{3}$ containing $55 \mathrm{mM}$ iodoacetamide in the dark at room temperature for $45 \mathrm{~min}$. The reduced and alkylated gel pieces were then subjected to 2 rounds of washing and dehydration with $100 \mu \mathrm{l}$ of $25 \mathrm{mM} \mathrm{NH}_{4} \mathrm{HCO}_{3}$ and $50 \%$ $\mathrm{ACN}$ in $25 \mathrm{mM} \mathrm{NH}_{4} \mathrm{HCO}_{3}$ for $10 \mathrm{~min}$. Gel pieces were dehydrated with $200 \mu \mathrm{l}$ of $100 \%$ ACN for $20 \mathrm{~min}$, and placed in a speedvac for $10 \mathrm{~min}$ to remove residual ACN. The gel pieces were reswollen by adding $20 \mu \mathrm{l}$ of $12.5 \mathrm{ng} \mathrm{ml}^{-1}$ trypsin (Promega) in $25 \mathrm{mM} \mathrm{NH}_{4} \mathrm{HCO}_{3}$ and incubated at $37^{\circ} \mathrm{C}$ overnight. The tryptic peptides were eluted from the gel with 2 sequential extractions using $20 \mu \mathrm{l}$ of $5 \%$ formic acid. The eluted peptides were then concentrated by using a speedvac.

Mass spectrometry protein identification. All samples were analyzed by LC/MS/MS using an LC Packings HPLC system equipped with a $5 \mathrm{~cm} \times 300 \mu \mathrm{m}$ PepMap $\mathrm{C}_{18}$ column. The separation was carried out using a linear gradient from 10 to $50 \%$ B over 20 min (A: $5 \% \mathrm{ACN}, 0.5 \%$ formic acid, B: $90 \% \mathrm{ACN}, 0.5 \%$ formic acid) at $5 \mathrm{ml} \mathrm{min}{ }^{-1}$. The HPLC was interfaced to an Applied Biosystems MDS SCIEX (Concord) Q TRAP mass spectrometer via a nanoflow source. Data was acquired in the information dependent acquisition mode, i.e. the specific mass to charge ratio $(\mathrm{m} / \mathrm{z})$ values of the tryptic peptides were measured using a high resolution scan (250 amu s${ }^{-1}$ ) and this scan was used to generate a peak list of peptides for tandem MS analysis. The tandem MS spectra were submitted to the database search program MASCOT (Matrix Science) in order to identify the proteins.

Database search. Two Aeromonas salmonicida strain A449 databases were used for MASCOT searches: (1) a nucleotide database consisting of all contigs in the latest A. salmonicida genome sequence assembly (R. Singh unpubl. data), and (2) a translated database of all A. salmonicida open reading frames (ORFs) with hits to GenBank that were identified in the A. salmonicida genome sequence assembly. The latter was constructed using a Perl script (written by Dr. M. Reith, National Research Council, Institute for Marine Biosciences [NRC-IMB]) to automate the identification and searching (BLASTP) of ORFs and the compilation of the ORF sequence with a description indicating its best GenBank hit.

\section{RESULTS}

\section{Validation of MASCOT search results}

The MASCOT search results were filtered using a Perl script that removed peptides with either scores below the $95 \%$ confidence limit or parent ion mass errors greater than $0.5 \mathrm{Da}$. After this editing proce-

Table 1. Summary of proteins identified from Fig. 1 Spot 16 by liquid chromatography/mass spectrometry/mass spectrometry (LC/MS/MS). m/z: specific mass to charge ratio. $\mathrm{M}_{\mathrm{r}}$ : relative molecular weight. Error: difference between measured mass and mass predicted from the DNA sequence. Score: s from MASCOT search; scores above $\sim 25$ are highly significant. Tryptic peptide sequence predicted from the DNA sequence

\begin{tabular}{|lccccc|}
\hline $\begin{array}{l}\text { Protein homolog } \\
\text { (NCBI accession no.) }\end{array}$ & $\begin{array}{c}\text { Parent ion } \\
(\mathrm{m} / \mathrm{z})\end{array}$ & $\mathrm{M}_{\mathrm{r}}(\mathrm{Da})$ & $\begin{array}{c}\text { Error } \\
(\mathrm{ppm})\end{array}$ & Score & Peptide sequence \\
\hline Putative lipoprotein & 407.85 & 813.68 & 15 & 31 & SLILLQK \\
(P28635) & 619.89 & 1237.76 & 6 & 113 & IVELEAAQLPR \\
& 826.50 & 1650.98 & 15 & 32 & EGAQIAVPNDPTNGLR \\
& 857.97 & 1713.92 & 5 & 43 & EGTGLEATVLDIASNPK \\
& 755.13 & 2262.38 & 18 & 41 & STDGLLTVAIR \\
Hypothetical protein & 573.38 & 1144.75 & 11 & 30 & TDLLELLTQQDK \\
(ZP_00015887) & & & & \\
Conserved hypothetical & 708.92 & 1415.83 & 8 & & \\
(XP_306643) & & & & & \\
\hline
\end{tabular}




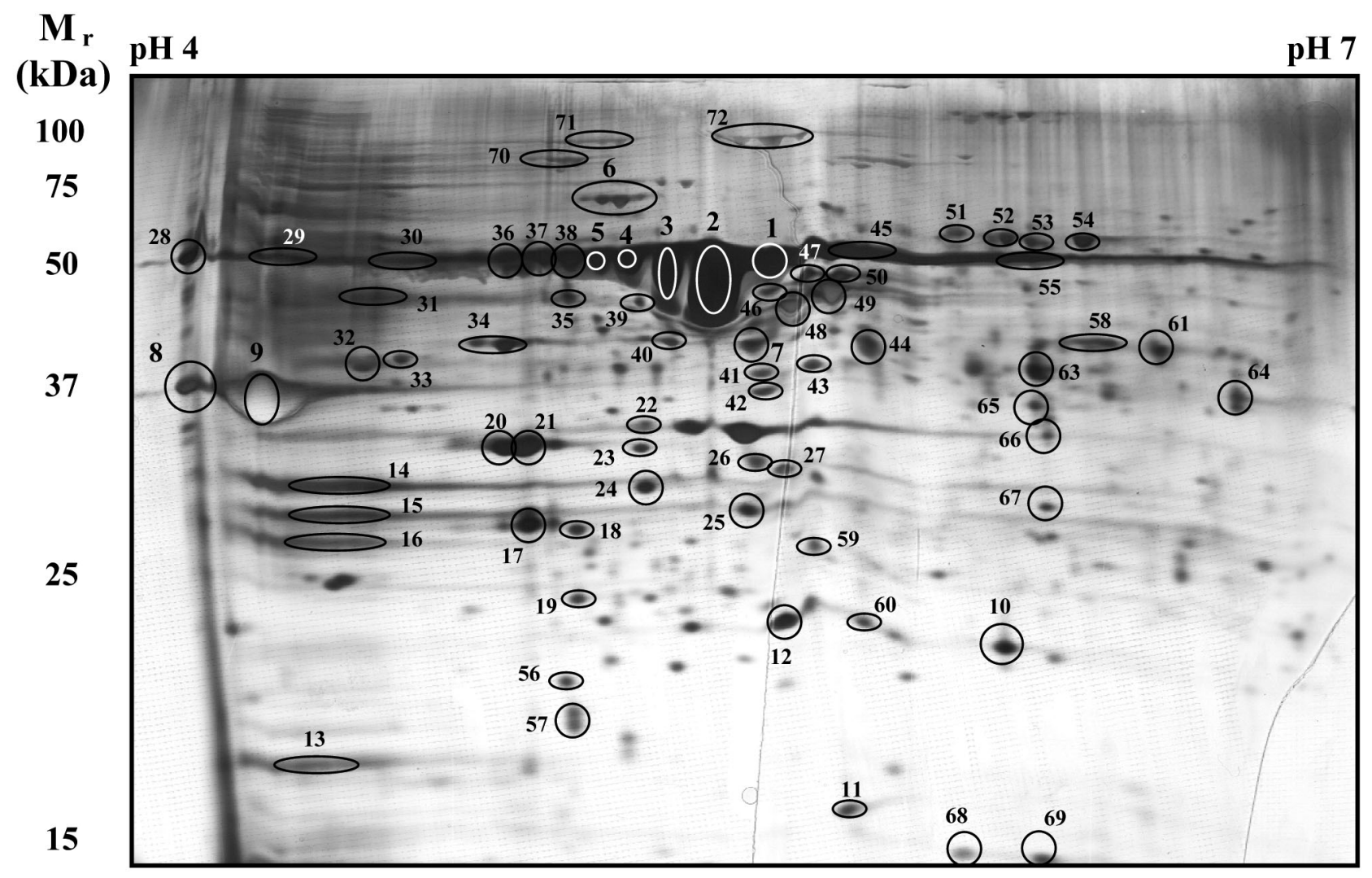

Fig. 1. Aeromonas salmonicida. 2-D gel electrophoresis of the carbonate-insoluble outer-membrane proteins expressed by A. salmonicida A 449 strain grown at $17^{\circ} \mathrm{C}$ in TSB. The carbonate-insoluble proteins were focused on a $17 \mathrm{~cm}$ pH $4-7 \mathrm{gel}$ followed by the second dimension separation on a $14 \%$ sodium dodecyl sulphate polyacrylamide gel electrophoresis (SDS-PAGE) gel. $\mathrm{M}_{\mathrm{r}}$ : relative molecular weight

dure, multiple proteins could sometimes be identified from individual spots. As an example, Table 1 shows the results from sequencing Spot 16 from Fig. 1. After the editing procedure, a total of 7 high quality sequenced peptides were identified which matched 3 Aeromonas salmonicida proteins. Five of these peptides matched a putative lipoprotein (D-methioninebinding lipoprotein, MetQ, Accession no. P28635), while one peptide was identified as matching a hypothetical protein (Accession no. ZP_00015887), and the other peptide matched an Anopheles gambiae protein (XP_306643), with homology to a phosphate transport regulator protein. The MASCOT scores of 41 and 30 for these respective peptides are above the sequence identity score (99\% confidence interval) of 27 , suggesting unambiguous sequence identification of these spots. Since the identification of the latter 2 proteins is based on single peptides, some degree of caution must be used with this data. In general, multiple identifications of distinct peptides from the same protein were obtained for greater than $80 \%$ of the proteins, leading to high confidence in our protein identifications. For proteins identified with 2 or more peptides, the aver- age number of peptides used for identification was 10 with a standard deviation of 8.2. For proteins identified using only a single peptide, the average MASCOT score was 41 with a standard deviation of 12.5. Proteins putatively identified from a single peptide are indicated with an * in Appendix 1 (available at: www.int-res.com/ articles/suppl/D068p029_app.pdf). For proteins identified using a single MS/MS spectrum, the sequences were verified manually.

\section{2-DE profile of Aeromonas salmonicida OMPs}

Membrane and cell surface proteins are intermediaries in the host-pathogen interactions during Aeromonas salmonicida infections. As such, they are of great importance in understanding $A$. salmonicida bacterial pathogenesis. To look at these surface proteins, we used a modified carbonate extraction protocol of Fujiki et al. (1982). Fig. 1 shows a typical silver stained 2-D gel of A. salmonicida OMPs grown in TSB to mid-log phase at $17^{\circ} \mathrm{C}$. We had previously established that virtually all the carbonate-extracted OMPs 
lie within a pI ranging from 4 to 7 (data not shown). The most striking aspect of the 2-D gel is the presence of the $49 \mathrm{kDa}$ S-layer protein (Spots 1-5, 28-30, 37, 38, 45 and 46). Seven distinct isoelectropherotypes of the S-layer protein are evident on the 2-D gel (Spots 1-5, 37 and 38). However, as evident from the identification of Spots 28-30, 45, and 46 as VapA, the S-layer protein is found at isoelectric points (pIs) ranging from 4 to above 6. Typically, the VapA protein isoelectropherotypes make up the vast majority of the total protein on the gel, which limits the analysis of the less abundant spots.

We were concerned that other surface proteins might be hidden due to the presence of the VapA protein. To address this, we prepared a carbonate extract and 2-D gel of Aeromonas salmonicida IMB 97-15 strain that lacks expression of the VapA protein. As shown in Fig. 2 and Appendix 1, this strain reveals the presence of 4 protein spots (Spots 84 to 87) that were hidden by the large VapA spots. Spots 84 to 86 have been identified as multiple isoelectropherotypes of a maltose-inducible porin, a homolog of the E. coli trimeric protein LamB. The other identified protein (Spot 87), apparently masked by the VapA protein was identified as a homolog of Haemophilus influenzae $\mathrm{Rd}$ KW20 H+-transporting 2-sector ATPase. The absence of the S-layer protein in the IMB 97-15 strain also clarified protein Spots 46, 47, 4849 and 50 in Fig. 1, which are distorted by the presence of the S-layer protein. In Fig. 2, these 5 Spots, (renumbered 88 to 91) can be more clearly seen and are identified in Appendix 1. Except for the S-layer protein contamination in the Fig. 1 spots, the same proteins were identified in both strains; however, spatial information was clearly lacking in the presence of the S-layer protein. As an example, Spot 49 in Fig. 1 was identified as outer membrane protein TolC, whereas the equivalent spot in the IMB 97-15 strain (Spot 93) was identified as being composed of 3 proteins; OMP TolC, agglutination protein and an OMP. Also identified from Fig. 2 are the same proteins identified in strain A449 (Spots 75 to 105).

One of the well-known limitations of 2-D electrophoresis is the limited solubility of high molecular weight, hydrophobic proteins. As evident from Fig. 1, proteins above $60 \mathrm{kDa}$ are not well represented. Initially, it was suggested that the low abundance of these high molecular weight (MW) proteins was due to the fact that the vast majority of proteins on the gel were the S-layer protein. However, the 2-D gel of the IMB 97-15 strain (Fig. 2), which lacks the S-layer protein, which should proportionately increase the less abundant proteins, did not significantly improve the situation. Fig. 3 shows the pI 4 to 9 and high MW section of a pI 3 to 10 gel of strain A449 grown under the same conditions as the previous samples but showing improved resolution of bands above $60 \mathrm{kDa}$. The identified bands are shown in Appendix 1, Spots 106 to119.

In total, 76 proteins from the outer membrane enriched fraction were successfully identified using electrospray ionization LC/MS/MS (Appendix 1), corresponding to $60 \%$ of the protein spots seen on the pI 4 to 72 -D gel. Numerous spots were identified that contained peptides from multiple proteins. Many of the identified Aeromonas salmonicida OMPs migrated as at least 2 charged species. These include VapA protein, OmpS1, OmpA, OmpK, FKBP-type peptidylprolyl isomerase, elongation factor Tu, enolase, ATP synthase alpha subunit and long-chain fatty acid transport protein. The specific nature of these protein isoelectropherotypes was not investigated further. Low-level spots judged to be below our detection level were not sequenced.



Fig. 2. Aeromonas salmonicida. 2-D gel electrophoresis of carbonate-insoluble outer membrane proteins expressed by the surface layer (S-layer) negative A. salmonicida IMB 97-15 strain grown at $17^{\circ} \mathrm{C}$ in TSB. The carbonate-insoluble proteins were focused on a $17 \mathrm{~cm} \mathrm{pH} \mathrm{4-7} \mathrm{gel} \mathrm{followed} \mathrm{by} \mathrm{the} \mathrm{second} \mathrm{dimension} \mathrm{separation} \mathrm{on} \mathrm{a} 14 \%$ SDS-PAGE gel. Note the absence of the S-layer protein. $\mathrm{M}_{\mathrm{r}}$ : relative molecular weight 


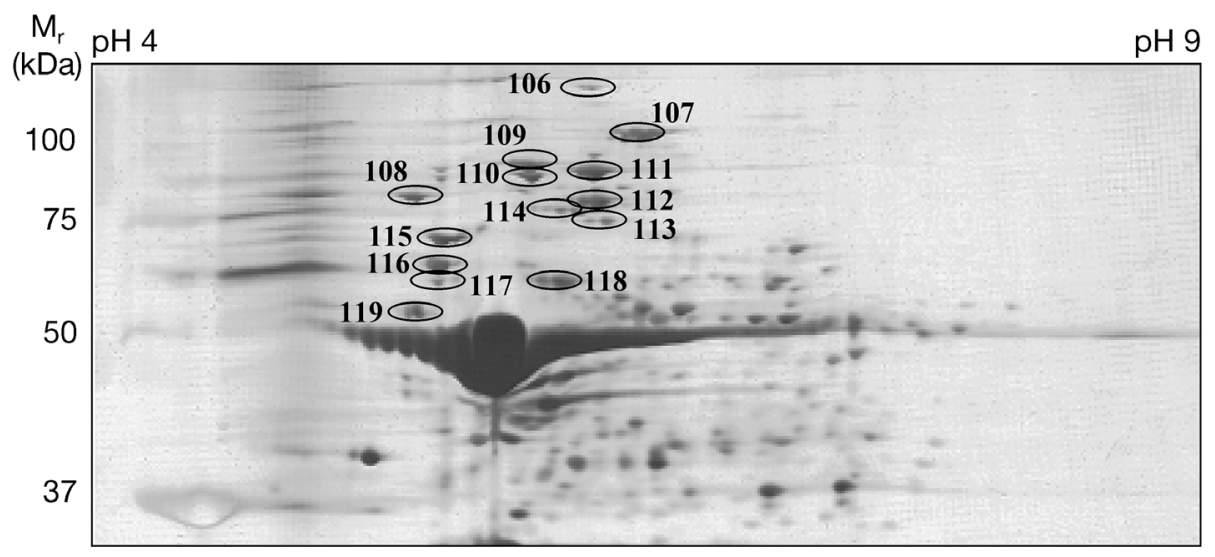

Fig. 3. Aeromonas salmonicida. 2-D gel electrophoresis ( $\mathrm{pH} 3-10$ ) of high molecular weight carbonate-insoluble outer membrane proteins expressed by $A$. salmonicida A449 strain grown at $17^{\circ} \mathrm{C}$ in TSB. The carbonate-insoluble proteins were focused on a $17 \mathrm{~cm} \mathrm{pH} \mathrm{3-10}$ gel followed by the second dimension separation on a $14 \%$ SDSPAGE gel. $\mathrm{M}_{\mathrm{r}}$ : relative molecular weight

\section{DISCUSSION}

The OMPs not only play a role in bacterial defence against host factors but also in virulence-related functions such as adhesion, invasion, and host cell modulation. The primary aim of this study was the proteomic characterization of the OMPs of Aeromonas salmonicida. In total, we identified 76 proteins from the carbonate enriched $A$. salmonicida membrane preparation. A number of these proteins have been previously identified in A. salmonicida; specifically Slayer (VapA), Cpn60 (groEL protein), OMPs AI/AII, maltose-inducible porin, ExeD, the secretin of the type II secretion pathway and the 3 outer membrane proteins upregulated in response to iron limitation (outer membrane heme receptor, siderophore receptor, and the ferric siderophore receptor). Not surprisingly, these proteins represent some of the most abundant proteins represented on the 2-Dgel. The multiple isoelectropherotypes of the S-layer protein (VapA) is the most prevalent protein expressed by far on the surface of $A$. salmonicida (Fig. 1, Spots 1-5, 37 and 38). It has been estimated that in order to cover its entire surface with the VapA protein, A. salmonicida needs to synthesize approximately 5000 copies of the VapA protein per second (Chu et al. 1993). The precise nature of the multiple isoelectropherotypes of the VapA protein in A. salmonicida has not been elucidated. However, evidence for VapA tyrosine phosphorylation has been presented by Thomas \& Trust (1995) on the related species A. hydrophila. The multiple isoelectropherotypes of VapA might also result from glycosylation. The precise role played by the VapA protein in the virulence of $A$. salmonicida has not been conclusively demonstrated; however, the protein is critical to bacterial virulence and has been shown to interact with a number of host-derived factors (Ishiguro et al. 1981, Munn et al. 1982, Phipps \& Kay 1988, Chu et al. 1991, Messner \& Sleytr 1991, Doig et al.
1992, Garduno et al. 1992, Kostrzynska et al. 1992, Trust et al. 1993).

Two-dimensional reference maps of the carbonate extracted membrane of Pseudomonas aeruginosa resolved from 300 to 350 protein spots on a pI 4 to 7 IPG strip. From the resolved spots, 189 were identified which corresponded to 104 genes (Nouwens et al. 2000). Using the same technique on the membranes of Caulobacter crescentus, Phadke and co-workers resolved approximately 200 spots, of which they managed to identify 120 corresponding to 54 unique proteins (Phadke et al. 2001). The 2-D gel of the carbonate-extracted membranes of A. salmonicida consistently resolved about 115 distinct spots. Eighty percent of these spots were identified corresponding to 76 unique proteins (Fig. 1, Table 1, Appendix 1). Compared to C. crescentus and $P$. aeruginosa, the reduced number of membrane proteins seen on the 2-D profile of $A$. salmonicida might be an intrinsic property of the bacteria; however, it might also be due to reduced efficiency of the carbonate extraction protocol with this organism.

A number of Aeromonas salmonicida OMPs (Appendix 1, Spots 8, 9,11, 16, 18, 19, 21, 27, 57, 70, and 95) have been identified as homologs of Anopheles gambiae str. PEST mosquito proteins. This suggests that a species of Aeromonas bacteria colonizes the gut of the A. gambiae mosquito and was sequenced as part of the malaria sequencing project. Evidence for such a relationship has been presented by Pidiyar and co-workers, who isolated a new species of Aeromonas (A. culicicola) from the midgut of the mosquitos Culex quinquefasciatus and Aedes aegyptii (Pidiyar et al. 2002). The actual number of $A$. salmonicida homologs from Aeromonas species colonizing A. gambiae midgut may be an underestimation, since the A. gambiae genome is not as yet annotated. Also, these hits were not always complete ORFs; therefore, to obtain annotated information, we looked at data from the next-best BLAST hits. The completion of the A. salmonicida 
genome should allow the filtering out of the majority of Aeromonas sequence data from the Anopheles gambiae sequencing project.

Initially, we were concerned that some of the proteins identified might be cytosolic proteins. While some cytosolic contamination was expected, the levels found for some of these proteins were surprisingly high. For example, we identified GroEL (Spot 6), elongation factor Tu (Spots 31, 35 and 48), elongation factor Ts (Spot 42), alkyl hydroperoxide reductase (Spot 12), FK 506 Binding protein (FKBP)-type peptidyl-prolyl isomerase (Spots 14 and 27), iron-cofactored superoxide dismutase (Spot 10), phosphoglycerate kinase (Spot 7) and enolase (Spots 46, 47 and 50), from our carbonate extraction protocol. None of these proteins are predicted to be OMPs by sequence analysis. The literature supports the association of some of these proteins with OMPs. Surface-exposed GroEL has been reported in Legionella pneumophila (Garduño et al. 1998a), Salmonella typhimurium (Ensgraber \& Loos 1992), and Clostridium difficile (Hennequin et al. 2001), to mention a few. Garduño and co-workers have shown that not only is Hsp60 surface exposed on L. neumophila but it is also selectively present on virulent strains and necessary for bacterial invasion (Garduno et al. 1998b). Proteomic analysis of the carbonate insoluble membranes of Pseudomonas aeruginosa also identified 3 of these proteins (FKBPtype peptidyl-prolyl isomerase, enolase and GroEL) (Nouwens et al. 2000). Using a phase separation system and a trifluoro-ethanol/chloroform mixture to extract E. coli K12 W3110 membrane proteins, Deshusses and co-workers not only found the expected membrane proteins but also phosphoglycerate kinase, elongation factor $\mathrm{Tu}$, alkylhydroperoxide reductase and iron-cofactored superoxide dismutase (Deshusses et al. 2003). Wong and co-workers have cloned the gene for Aeromonas hydrophila FK506 binding protein (Wong et al. 1997). Sequence analysis of the FK506 binding protein suggests the protein may be membrane bound via an N-myristoylation site. The deduced amino acid sequence of the A. salmonicida FKBP-type peptidylprolyl isomerase has $98 \%$ amino acid identity with the FK506 binding protein from A. hydrophila and the putative $\mathrm{N}$-myristoylation sequence is conserved (data not shown). Elongation factor Tu has been shown to be methylated and become membrane associated in response to various stimuli (Young \& Bernlohr 1991). Cell surface localization of elongation factor Tu was also reported by Dallo and co-workers (2002). They reported that 2 Mycoplasma pneumoniae cytoplasmic proteins, elongation factor Tu and pyruvate dehydrogenase E1 ${ }^{\beta}$ subunit, exhibit a surface location and mediate $M$. pneumoniae binding to fibronectin. As mentioned above, phosphoglycerate kinase has been identified as a constituent of the outer membrane of Streptococcus agalactiae (Deshusses et al. 2003). The outer surface localization was confirmed by raising antisera to the phosphoglycerate kinase and showing reactivity to whole live bacteria. The above authors also demonstrated that the antisera to phosphoglycerate kinase offered some degree of protection against a neonatal infection model.

Enolase is an essential glycolytic enzyme that catalyzes the interconversion of 2-phosphoglycerate and phosphoenolpyruvate. Like GroEL and possibly the other non-classical membrane protein mentioned above, surface localization of enolase has been reported in a number of Gram-positive and Gram-negative bacterial organisms (Hara et al. 2000, Bergmann et al. 2001, Pancholi 2001, Hughes et al. 2002, Sha et al. 2003). The surface expression of enolase is implicated in the binding and activation of plasminogen in humans, leading to a number of pathophysiological responses (Redlitz et al. 1995, Fontan et al. 2000, Gitlits et al. 2001, Pancholi 2001, Maruyama et al. 2002). Sha and co-workers demonstrated the cell surface expression of enolase in Aeromonas hydrophila and that the gene exhibited increased expression under in vivo growth conditions (Sha et al. 2003). Therefore, the identification of elongation factors $\mathrm{Tu}$ and $\mathrm{Ts}$, alkyl hydroperoxide reductase, FKBP-type peptidyl-prolyl isomerase, iron-cofactored superoxide dismutase, phosphoglycerate kinase, enolase and other proteins normally considered to be cytoplasmic in the carbonate insoluble fraction warrants further investigation. The association of these proteins with the A. salmonicida cell surface might provide new insights concerning the biological and pathogenic roles of these molecules in A. salmonicida infection.

Aeromonas salmonicida, like other Gram-negative bacteria, has 2 membrane layers. The outer membrane has many functions, one of which is a selective permeation barrier (Nikaido 2003). Bacterial outer membranes contain channel-forming proteins that function in osmoregulation, nutrient acquisition and export of proteins and waste products. We have identified at least 10 outer membrane porin-type molecules in the carbonate-extracted membrane proteome of A. salmonicida. These include homologs of OMP C (Spot 8), OMP AI/AII (Spots 17, 20, 21, 22, 23, 25 and 26), OMP K (Spots 18 and 19), OMP TolC (Spots 49 and 50), OMP D (Spots 62 and 63) and other outer membrane porins not yet properly annotated (Spots 32 and 48). Other OMPs involved in nutrient acquisition include long chain fatty acid transport protein (Spots 24 and 39), exo-1, 4- $\beta$-glucosidase (Spot 111) and the IROMPs previously described (Spots 120 to 122, respectively).

Other groups, as well as ours, have previously established that in response to iron limitation, Aeromo- 
nas salmonicida up-regulates at least 3 OMPs involved in iron recruitment (Chart \& Trust 1983, Hirst et al. 1991, Neelam et al. 1993, Fernandez et al. 1998, Ebanks et al. 2004). Growth under iron-restricted conditions resulted in the expression of outer-membrane proteins of 73,76 and $85 \mathrm{kDa}$, which were identified as a siderophore receptor, an outer membrane heme receptor and a ferric siderophore receptor, respectively (Ebanks et al. 2004). These proteins were not detected in bacteria in the presence of iron; the only protein identified with a role in iron recruitment was an uncharacterized enzyme of heme biosynthesis (Spots 41 and 43). BLAST analysis suggests the protein might be a homolog of Vibrio parahaemolyticus uroporphyrin-III C-methyltransferase. The iron-dependent expression of iron recruitment receptors suggests strict control of the intracellular iron concentration within A. salmonicida.

In general, most S-layer proteins are composed of a single protein or glycoprotein species with an intrinsic ability to self assemble into regular paracrystalline arrays. The S-layer lattices are thought to cover the cell surface during all stages of growth (Boot \& Pouwels 1996). To date, the only Aeromonas salmonicida outer membrane components that have been shown to be antigenic include the S-layer protein, the O-polysaccharide component of LPS and the iron-regulated OMPs (Evenberg et al. 1985, Magnadottir \& Gudmundsdottir 1992, Magnadottir et al. 1995, Ellis 1997, Ellis et al. 1997). The putative OMP proteins identified in this study might be candidates for immunization against furunculosis (Phadnis et al. 1996, Frisk et al. 1998, Marcus \& Scott 2001).

In this study we describe the first attempt to identify Aeromonas salmonicida OMPs using a direct proteomic approach. Bacterial outer membrane components as well as the secreted proteins represent the interphase between the host and the invading bacterium. As such, the A. salmonicida outer membrane proteome presented here will be useful for identifying proteins involved in virulence and which possess antigenic potential for the development of novel vaccines. The outer membrane proteome of A. salmonicida should also allow us to look at the A. salmonicida outer membrane architecture and the immunological response of the host to infection.

Acknowledgements. The authors acknowledge the kind gift of the Aeromonas strains used in this study from Dr. Bill Kay of the University of British Columbia and Gilles Olivier from the Department of Fisheries and Oceans, Moncton, NB. They also acknowledge the assistance of Dr. Jessica Boyd, Dr. Michael Reith, Dr. Rama Singh and Bruce Curtis of the National Research Council of Canada's Institute for Marine Biosciences (NRC-IMB). This is NRCC publication 200542563

\section{LITERATURE CITED}

Bergmann S, Rohde M, Chhatwal GS, Hammerschmidt S (2001) Alpha-enolase of Streptococcus pneumoniae is a plasmin(ogen)-binding protein displayed on the bacterial cell surface. Mol Microbiol 40:1273-1287

Beveridge TJ, Pouwels PH, Sara M, Kotiranta A, and 21 others (1997) Functions of S-layers. FEMS Microbiol Rev 20: 99-149

Bjornsdottir R, Eggset G, Nilsen R, Jorgensen TO (1992) The A-layer protein of Aeromonas salmonicida: further characterization and a new isolation procedure. J Fish Dis 15: 105-118

Blonder J, Goshe MB, Moore RJ, Pasa-Tolic L, Masselon CD, Lipton MS, Smith RD (2002) Enrichment of integral membrane proteins for proteomic analysis using liquid chromatography-tandem mass spectrometry. J Proteome Res 1:351-360

Boot HJ, Pouwels PH (1996) Expression, secretion and antigenic variation of bacterial S-layer proteins. Mol Microbiol 21:1117-1123

Bradford MM (1976) A rapid and sensitive method for the quantitation of microgram quantities of protein utilizing the principle of protein-dye binding. Anal Biochem 72: $248-254$

Chart H, Trust TJ (1983) Acquisition of iron by Aeromonas salmonicida. J Bacteriol 156:758-764

Chu S, Cavaignac S, Feutrier J, Phipps BM, Kostrzynska M, Kay WW, Trust TJ (1991) Structure of the tetragonal surface virulence array protein and gene of Aeromonas salmonicida. J Biol Chem 266:15258-15265

Chu S, Gustafson CE, Feutrier J, Cavaignac S, Trust TJ (1993) Transcriptional analysis of the Aeromonas salmonicida Slayer protein gene vapA. J Bacteriol 175:7968-7975

Costello GM, Vipond R, MacIntyre S (1996) Aeromonas salmonicida possesses two genes encoding homologs of the major outer membrane protein, OmpA. J Bacteriol 178: 1623-1630

Dallo SF, Kannan TR, Blaylock MW, Baseman JB (2002) Elongation factor Tu and E1 beta subunit of pyruvate dehydrogenase complex act as fibronectin binding proteins in Mycoplasma pneumoniae. Mol Microbiol 46:1041-1051

Darveau RP, MacIntyre S, Buckley JT, Hancock RE (1983) Purification and reconstitution in lipid bilayer membranes of an outer membrane, pore-forming protein of Aeromonas salmonicida. J Bacteriol 156:1006-1011

Deshusses JM, Burgess JA, Scherl A, Wenger Y and 6 others (2003) Exploitation of specific properties of trifluoroethanol for extraction and separation of membrane proteins. Proteomics 3:1418-1424

Dodsworth SJ, Bennett AJ, Coleman G (1993) Molecular cloning and nucleotide sequence analysis of the maltoseinducible porin gene of Aeromonas salmonicida. FEMS Microbiol Lett 112:191-197

Doig P, Emody L, Trust TJ (1992) Binding of laminin and fibronectin by the trypsin-resistant major structural domain of the crystalline virulence surface array protein of Aeromonas salmonicida. J Biol Chem 267:43-49

Ebanks RO, Dacanay A, Goguen M, Pinto DM, Ross NW (2004) Differential proteomic analysis of Aeromonas salmonicida outer-membrane proteins in response to lowiron and in vivo growth conditions. Proteomics 4: 1074-1085

Ellis AE (1997) Immunization with bacterial antigens: furunculosis. Dev Biol Stand 90:107-116

Ellis AE, do Vale A, Bowden TJ, Thompson $\mathrm{K}$, Hastings TS (1997) In vivo production of A-protein, lipopolysaccharide, 
iron-regulated outer membrane proteins and 70-kDa serine protease by Aeromonas salmonicida subsp. salmonicida. FEMS Microbiol Lett 149:157-163

Ensgraber M, Loos M (1992) A 66-kilodalton heat shock protein of Salmonella typhimurium is responsible for binding of the bacterium to intestinal mucus. Infect Immun 60:3072-3078

Evenberg D, Versluis R, Lugtenberg B (1985) Biochemical and immunological characterization of the cell surface of the fish pathogenic bacterium Aeromonas salmonicida. Biochim Biophys Acta 815:233-244

Fernandez AI, Fernandez AF, Perez MJ, Nieto TP, Ellis AE (1998) Siderophore production by Aeromonas salmonicida subsp. salmonicida. Lack of strain specificity. Dis Aquat Org 33:87-92

Fontan PA, Pancholi V, Nociari MM, Fischetti VA (2000) Antibodies to streptococcal surface enolase react with human alpha-enolase: implications in poststreptococcal sequelae. J Infect Dis 182:1712-1721

Frisk A, Ison CA, Lagergard T (1998) GroEL heat shock protein of Haemophilus ducreyi: association with cell surface and capacity to bind to eukaryotic cells. Infect Immun 66: 1252-1257

Fujiki Y, Hubbard AL, Fowler S, Lazarow PB (1982) Isolation of intracellular membranes by means of sodium carbonate treatment: application to endoplasmic reticulum. J Cell Biol 93:97-102

Garduño RA, Lee EJ, Kay WW (1992) S-layer-mediated association of Aeromonas salmonicida with murine macrophages. Infect. Immun. 60:4373-4382

Garduño RA, Faulkner G, Trevors MA, Vats N, Hoffman PS (1998a) Immunolocalization of Hsp60 in Legionella pneumophila. J Bacteriol 180:505-513

Garduño RA, Garduño E, Hoffman PS (1998b) Surface-associated hsp60 chaperonin of Legionella pneumophila mediates invasion in a HeLa cell model. Infect Immun 66: 4602-4610

Gitlits VM, Toh BH, Sentry JW (2001) Disease association, origin, and clinical relevance of autoantibodies to the glycolytic enzyme enolase. J Investig Med 49:138-145

Glauert AM, Thornley MJ (1969) The topography of the bacterial cell wall. Annu Rev Microbiol 23:159-198

Hara H, Ohta H, Inoue T, Ohashi T, Takashiba S, Murayama Y, Fukui K (2000) Cell surface-associated enolase in Actinobacillus actinomycetemcomitans. Microbiol Immunol 44:349-356

Hennequin C, Porcheray F, Waligora-Dupriet A, Collignon A, Barc M, Bourlioux P, Karjalainen T (2001) GroEL (Hsp60) of Clostridium difficile is involved in cell adherence. Microbiology 147:87-96

Hirst ID, Ellis AE (1994) Iron-regulated outer membrane proteins of Aeromonas salmonicida are important protective antigens in Atlantic salmon against furunculosis. Fish Shellfish Immunol. 4:29-45

Hirst ID, Hastings TS, Ellis AE (1991) Siderophore production by Aeromonas salmonicida. J Gen Microbiol 137 (Pt 5): 1185-1192

Hughes MJ, Moore JC, Lane JD, Wilson R and 12 others (2002) Identification of major outer surface proteins of Streptococcus agalactiae. Infect Immun 70:1254-1259

Ishiguro EE, Kay WW, Ainsworth T, Chamberlain JB, Austen RA, Buckley JT, Trust TJ (1981) Loss of virulence during culture of Aeromonas salmonicida at high temperature. J Bacteriol 148:333-340

Janda JM, Duffey PS (1988) Mesophilic aeromonads in human disease: current taxonomy, laboratory identification, and infectious disease spectrum. Rev Infect Dis 10: 980-997
Janda JM, Kokka RP (1991) The pathogenicity of Aeromonas strains relative to genospecies and phenospecies identification. FEMS Microbiol Lett 69:29-33

Karlyshev AV, MacIntyre S (1995) Cloning and study of the genetic organization of the exe gene cluster of Aeromonas salmonicida. Gene 158:77-82

Kostrzynska M, Dooley JS, Shimojo T, Sakata T, Trust TJ (1992) Antigenic diversity of the S-layer proteins from pathogenic strains of Aeromonas hydrophila and Aeromonas veronii biotype sobria. J Bacteriol 174:40-47

Logan SM, Trust TJ (1983) Molecular identification of surface protein antigens of Campylobacter jejuni. Infect Immun 42:675-682.

Lutwyche P, Exner MM, Hancock RE, Trust TJ (1995) A conserved Aeromonas salmonicida porin provides protective immunity to rainbow trout. Infect Immun 63:3137-3142

Magnadottir B, Gudmundsdottir BK (1992) A comparison of total and specific immunoglobulin levels in healthy Atlantic salmon (Salmo salar L.) and in salmon naturally infected with Aeromonas salmonicida subsp. achromogenes. Vet Immunol Immunopathol 32:179-189

Magnadottir B, Gudmundsdottir S, Gudmundsdottir BK (1995) Study of the humoral response of Atlantic salmon (Salmo salar L.), naturally infected with Aeromonas salmonicida ssp. achromogenes. Vet Immunol Immunopathol 49:127-142

Marcus EA, Scott DR (2001) Cell lysis is responsible for the appearance of extracellular urease in Helicobacter pylori. Helicobacter 6:93-99

Maruyama I, Maeda T, Okisaka S, Mizukawa A, Nakazawa M, Ohguro H (2002) Autoantibody against neuron-specific enolase found in glaucoma patients causes retinal dysfunction in vivo. Jpn J Ophthalmol 46:1-12

Messner P, Sleytr UB (1991) Bacterial surface layer glycoproteins. Glycobiology 1:545-551

Molloy MP, Herbert BR, Slade MB, Rabilloud T, Nouwens AS, Williams KL, Gooley AA (2000) Proteomic analysis of the Escherichia coli outer membrane. Eur J Biochem 267: 2871-2881

Munn CB, Ishiguro EE, Kay WW, Trust TJ (1982) Role of surface components in serum resistance of virulent Aeromonas salmonicida. Infect Immun 36:1069-1075

Neelam B, Robinson RA, Price NC, Stevens L (1993) The effect of iron limitation on the growth of Aeromonas salmonicida. Microbios 74:59-67

Nikaido H (2003) Molecular basis of bacterial outer membrane permeability revisited. Microbiol Mol Biol Rev 67: 593-656

Nouwens AS, Cordwell SJ, Larsen MR, Molloy MP, Gillings M, Willcox MD, Walsh BJ (2000) Complementing genomics with proteomics: the membrane subproteome of Pseudomonas aeruginosa PAO1. Electrophoresis 21: 3797-3809

Pancholi V (2001) Multifunctional alpha-enolase: its role in diseases. Cell Mol Life Sci 58:902-920

Phadke ND, Molloy MP, Steinhoff SA, Ulintz PJ, Andrews PC, Maddock JR (2001) Analysis of the outer membrane proteome of Caulobacter crescentus by two-dimensional electrophoresis and mass spectrometry. Proteomics 1: 705-720

Phadnis SH, Parlow MH, Levy M, Ilver D, Caulkins CM, Connors JB, Dunn BE (1996) Surface localization of Helicobacter pylori urease and a heat shock protein homolog requires bacterial autolysis. Infect Immun 64:905-912

Phipps BM, Kay WW (1988) Immunoglobulin binding by the regular surface array of Aeromonas salmonicida. J Biol Chem 263:9298-9303 
Pidiyar V, Kaznowski A, Narayan NB, Patole M, Shouche YS (2002) Aeromonas culicicola sp. nov., from the midgut of $\mathrm{Cu}$ lex quinquefasciatus. Int J Syst Evol Microbiol 52:1723-1728

Redlitz A, Fowler BJ, Plow EF, Miles LA (1995) The role of an enolase-related molecule in plasminogen binding to cells. Eur J Biochem 227:407-415

Sara M, Sleytr UB (2000) S-Layer proteins. J Bacteriol 182: 859-868

Sha J, Galindo CL, Pancholi V, Popov VL, Zhao Y, Houston CW, Chopra AK (2003) Differential expression of the enolase gene under in vivo versus in vitro growth conditions of Aeromonas hydrophila. Microb Pathog 34:195-204

Shevchenko A, Wilm M, Vorm O, Mann M (1996) Mass spectrometric sequencing of proteins silver-stained polyacrylamide gels. Anal Chem 68:850-858

Sleytr UB, Beveridge TJ (1999) Bacterial S-layers. Trends Microbiol 7:253-260

Editorial responsibility: Carey Cunningham, Aberdeen, UK
Thomas SR, Trust TJ (1995) Tyrosine phosphorylation of the tetragonal paracrystalline array of Aeromonas hydrophila: molecular cloning and high-level expression of the S-layer protein gene. J Mol Biol 245:568-581

Trust TJ, Kostrzynska M, Emody L, Wadstrom T (1993) Highaffinity binding of the basement membrane protein collagen type IV to the crystalline virulence surface protein array of Aeromonas salmonicida. Mol Microbiol 7: 593-600

Wong CY, Heuzenroeder MW, Quinn DM, Flower RL (1997) Cloning and characterization of two immunophilin-like genes, ilpA and fkpA, on a single 3.9-kilobase fragment of Aeromonas hydrophila genomic DNA. J Bacteriol 179: 3397-3403

Young CC, Bernlohr RW (1991) Elongation factor Tu is methylated in response to nutrient deprivation in Escherichia coli. J Bacteriol 173:3096-3100

Submitted: March 3, 2005; Accepted: June 7, 2005

Proofs received from author(s): November 21, 2005 